\title{
BMJ Open How was cognitive behavioural therapy for mood disorder implemented in Japan? A retrospective observational study using the nationwide claims database from FY2010 to FY2015
}

To cite: Hayashi Y, Yoshinaga N, Sasaki Y, et al. How was cognitive behavioural therapy for mood disorder implemented in Japan? A retrospective observational study using the nationwide claims database from FY2010 to FY2015. BMJ Open 2020;10:e033365. doi:10.1136/ bmjopen-2019-033365

- Prepublication history and additional material for this paper are available online. To view these files, please visit the journal online (http://dx.doi org/10.1136/bmjopen-2019033365).

Received 01 August 2019 Revised 25 February 2020 Accepted 14 April 2020
Check for updates

(C) Author(s) (or their employer(s)) 2020. Re-use permitted under CC BY-NC. No commercial re-use. See rights and permissions. Published by BMJ.

For numbered affiliations see end of article.

Correspondence to Dr Naoki Yoshinaga; naoki-y@med.miyazaki-u.ac.jp

\section{ABSTRACT}

Objectives To clarify the dissemination status of cognitive behavioural therapy (CBT) in Japan under the national health insurance scheme.

Design Retrospective observational study.

Setting National Database of Health Insurance Claims and Specific Health Checkups of Japan.

Participants Patients who received CBT under the national health insurance scheme from fiscal years (FY) 2010 to 2015.

Primary and secondary outcome measures We estimated the change rate and the standardised claim ratio (SCR) for the number of patients receiving CBT and analysed the association between the CBT status and several regional factors.

Results We found that (a) a total of 60304 patients received CBT during the study period; (b) the number of patients receiving $\mathrm{CBT}$ was highest in the first year $(-1.8 \%$ from FY2010 to FY2015); (c) the number of patients who received CBT per 100000 population decreased (or remained at zero) in most prefectures (32 out of 47); (d) there was a maximum 424.7-fold difference between prefectures in the standardised claim ratio for CBT and (e) the number of registered $\mathrm{CBT}$ institutions was significantly associated with the number of patients who received CBT. Conclusions The provision of CBT did not increase in the first 6 years (FY2010-2015) after its coverage in Japan's national health insurance scheme. Further studies including a questionnaire survey of registered CBT institutions are required to get more detailed information on the dissemination of CBT in Japan.

\section{INTRODUCTION}

Disseminating effective treatment for psychiatric disorders is urgently required around the world. Mathers and Loncar ${ }^{1}$ reported that major depression is predicted to be the leading cause of burden of disease in high-income countries by 2030; HIV/AIDS and perinatal disorders rank higher only in low-income and middle-income countries.

\section{Strengths and limitations of this study}

This is the first study to describe the provision status of cognitive behavioural therapy (CBT) in Japan using a nationwide database which covers all electronic claims in Japan's national health insurance system.

- The main limitation of this study is that our data do not include medical treatment data for any treatment provided outside the national system (eg, private counselling).

- The ecological analysis was conducted using specific variables, so there could be other factors which affect the provision of CBT.

Although mood disorders including major depression have been reported to be less prevalent in Asian countries than in Western countries, they have become more common among Japanese since the 2000s, which might reflect the Japanese government's attempt to raise people's awareness of mental health. ${ }^{23}$ The rate of mental health service use in Japan has also increased in the past 20 years. ${ }^{4}$

Since the 1980s, effective psychological interventions for a wide range of psychiatric disorders have been empirically developed. Among them, cognitive behavioural therapy (CBT) has consistently been shown to be effective for various psychiatric disorders on both a short-term basis and a longterm basis, ${ }^{5-13}$ and has also been a strongly recommended treatment option for both inpatients and outpatients in national guidelines. ${ }^{14-18}$ Importantly, patients often desire to receive psychotherapy rather than pharmacotherapy. ${ }^{19}{ }^{20}$ However, there is evidence that empirically supported CBT is rarely available 
(or is delivered suboptimally) in routine clinical care in Western countries. ${ }^{21}{ }^{22}$

In order to address the problem, in 2008 England's National Health Service (NHS) instigated a therapists' postqualification training programme, the English Improving Access to Psychological Therapies (IAPT) programme. The IAPT training programme is delivered as a joint venture between universities and clinical services, and has been implemented across England. Over a 1 year training period, high-intensity trainees (providing traditional face-to-face therapy) attend a university-based course for lectures, workshops and case supervision 2 days a week, while low-intensity trainees (providing guided selfhelp, brief therapy, etc.) attend university for 1 day per week. For the rest of their time, both sets of trainees work in an IAPT service where they receive further regular supervision. For the first 10 years of the IAPT, the number of patients who received psychotherapy (including CBT) increased markedly (from 181947 patients in fiscal year (FY) 2009 to 1092296 patients in FY2018). ${ }^{23} 24$

In Japan, CBT was introduced to the psychiatric field in the late 1980s. ${ }^{25}$ Since FY2010, CBT for outpatients with mood disorders has been covered by the national health insurance scheme. This marked a milestone in Japanese mental health service where pharmacotherapy has historically been much more common. ${ }^{26-28}$ Subsequently, since FY2011, the Japanese Ministry of Health Labour and Welfare (MHLW) has started to organise training for therapists to disseminate CBT. However, it is still unclear whether CBT is routinely implemented in Japanese clinical settings under the national health insurance scheme. Two studies have employed a questionnaire method to investigate the capability of providing CBT in Japanese psychiatric institutions, but the very low return/response rates $(16.5 \%$ and $20.3 \%)$ limit the generalisability of the findings. $^{29} 30$

The current study aims to assess the dissemination status of CBT in the first 6years (FY2010-2015) after its inclusion in the national insurance scheme in Japan, using the nationwide claims database. We selected ambulatory psychotherapy, provided in the routine psychiatric outpatient care, as a reference. Data on the actual dissemination status of CBT (including regional variations) have never been widely available, and such data are needed to estimate the unmet need for services, to promote open discussion between policy makers and general public, and to guide mental healthcare policy initiatives in the future.

\section{METHODS}

\section{Main data source and extracted data}

The present retrospective observational study was conducted using data from the National Database of Health Insurance Claims and Specific Health Checkups of Japan (NDB), a Japanese nationwide health insurance claims database operated by the MHLW. Japan uses a universal healthcare system, patients pay $10 \%-30 \%$ of their total medical fees according to patients' age and socioeconomic status. To earn all medical fees, medical care facilities have to submit medical fee claims to their municipality (see online supplementary figure 1 ). The NDB has all electronic claims, $99 \%$ of all claims issued from hospitals and clinics, ${ }^{31}$ and stores approximately 1.9 billion claims annually. The claims data contains various clinical and procedural information, such as patients' sex, age, month of examination, diagnostic code, medical practice code, drug code and hospital code. Personally identifiable data (eg, name, beneficiary identification number, date of birth) are automatically converted into hash values at the time of storage in NDB to make it irreversibly anonymous.

We used accumulated NDB data from FY2010 to FY2015 regarding CBT [code 180035910 and 180033210$]$. We also collected NDB data regarding ambulatory psychotherapy as a reference ( $\geq 30$ min (code 180012210) and $<30$ min (code 180031010$)$ ). Ambulatory psychotherapy in the national health insurance scheme includes any type of psychotherapy (eg, supportive psychotherapy) implemented by psychiatrists in routine outpatient care. We chose this as a reference to CBT because (1) both psychotherapies target only outpatients and (2) both are provided only by a medical doctor (table 1). CBT and ambulatory psychotherapy cannot be ticked at the same time. Extracted NDB data provided the exact number of patients who received each psychotherapy in each age group and prefecture. Each patient was counted as 'one' even though the patient received more than one session. We did not collect diagnostic codes because it is said that diagnostic codes in NDB do not reflect the actual patient's diagnosis due to insurance claims needs. ${ }^{32}$ To address the uncertainty/inaccuracy of diagnostic codes in NDB, some studies have combined diagnostic codes with other reliable examination or treatment codes (eg, breast cancer code and cancer treatment codes (surgery/ chemotherapy/medication/radiation procedure)). ${ }^{33}$ However, in the psychiatric field, diagnostic codes in NDB are usually based on medical doctors' own judgement, and there are no other reliable examination or treatment codes to determine specific disorders. Therefore, we only focused on reliable medical practice codes in this study.

\section{Analysis}

First, we calculated the change rate for the number of patients who received CBT or ambulatory psychotherapy from FY2010 through FY2015. A baseline for the rate of change for each psychotherapy was the number of patients in FY2010. Second, we calculated the number of patients who received each psychotherapy per 100000 population, and then assessed the increase or decrease in patients between FY2010 and FY2015 by prefecture. Third, we calculated the standardised claim ratio (SCR) for the number of patients who received CBT. The indicator is based on the same logic as the standardised mortality ratio (eg, it signifies that a prefecture with an SCR over 100 has more patients who received CBT than 
Table 1 CBT and ambulatory psychotherapy in Japan's national health insurance scheme

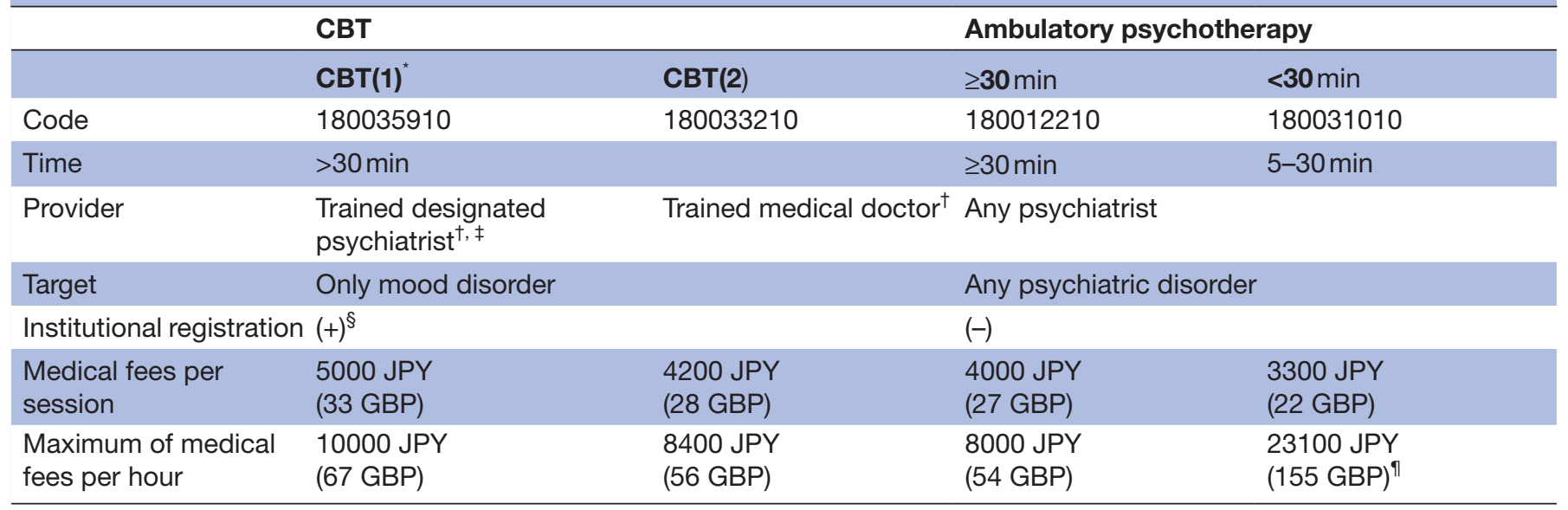

Exchange rate: $1 \mathrm{GBP}=150 \mathrm{JPY}$.

${ }^{*} \mathrm{CBT}(1)$ have been established since fiscal year 2012.

tWho received some kind of any training for CBT.

fDesignated psychiatrist (Mental Health and Welfare Law-authorised) who also cooperates with local psychiatric emergency medical services (eg, holiday/night medical examinations).

§Institutions need to register their institution's name along with CBT providers' names (trained designated psychiatrists or trained medical doctors) to the Regional Bureau of Health and Welfare of Japan.

ПAssuming that a psychiatrist sees seven patients per hour. ${ }^{35}$

$\mathrm{CBT}$, cognitive behavioural therapy; GBP, Great Britain pound; JPY, Japanese yen.

the national mean). The SCR is calculated according to the following formula:

$$
\begin{aligned}
& \text { SCR }=\frac{\sum \text { Observed number }(\mathrm{N}) \text { of claims }}{\sum \text { Expected } \mathrm{N} \text { of claims }} \times 100 \\
& =\frac{\sum \text { Observed } \mathrm{N} \text { of claims by age group } \times 100}{\sum \text { Population by age group } \times \text { Claim rate by age group }} \\
& =\frac{\sum \text { Observed } \mathrm{N} \text { of claims by age group } \times 100}{\sum \text { Population by age group } \times \frac{\text { Observed } \mathrm{N} \text { of claims by age group in Japan }}{\text { Population by age group in Japan }}}
\end{aligned}
$$

Fourth, in order to assess regional factors related to the provision of CBT, we examined associations between CBT patients per 100000 population and the following variables: (1) registered institutions for CBT per 100000 population from Regional Bureau of Health and Welfare of Japan and (2) psychiatrists per 100000 population from the portal site for Japanese Government Statistics, by using linear mixed effects models. Fixed effects were the above three variables and year; prefecture was included as a random effect. We also investigated the association between SCR for CBT and the implementation of formal CBT training (organised by the MHLW) using the independent t-test. The dependent variable was SCR for CBT, and the independent variables were prefecture groups that had been classified according to whether or not formal CBT training had been implemented (at least one time). Significant differences were indicated at $\mathrm{p}$ value $<0.05$. Data were analysed using the SAS software V.9.4 (SAS Institute).

\section{Patient and public involvement}

Patients or public were not involved in this study.

\section{RESULTS}

During the study period (FY2010-2015), 60304 patients received CBT and 34628225 patients received ambulatory psychotherapy. There is no big difference in terms of demographic data between these psychotherapies: more women than men received each psychotherapy, with most patients (men and women) being aged between 20 and 59 years (see online supplementary table 1 ). As for trends over time (figure 1), the number of patients who received CBT dropped in FY2012 and thereafter recovered slightly from FY2013, but not to the level of FY2010 (when CBT was first added to the health insurance scheme). CBT patients decreased by $1.8 \%$ from FY2010 to FY2015. In contrast, the number of patients who received both types of ambulatory psychotherapy continued to increase; of these, ambulatory psychotherapy $(\geq 30 \mathrm{~min})$ increased dramatically from FY2012.

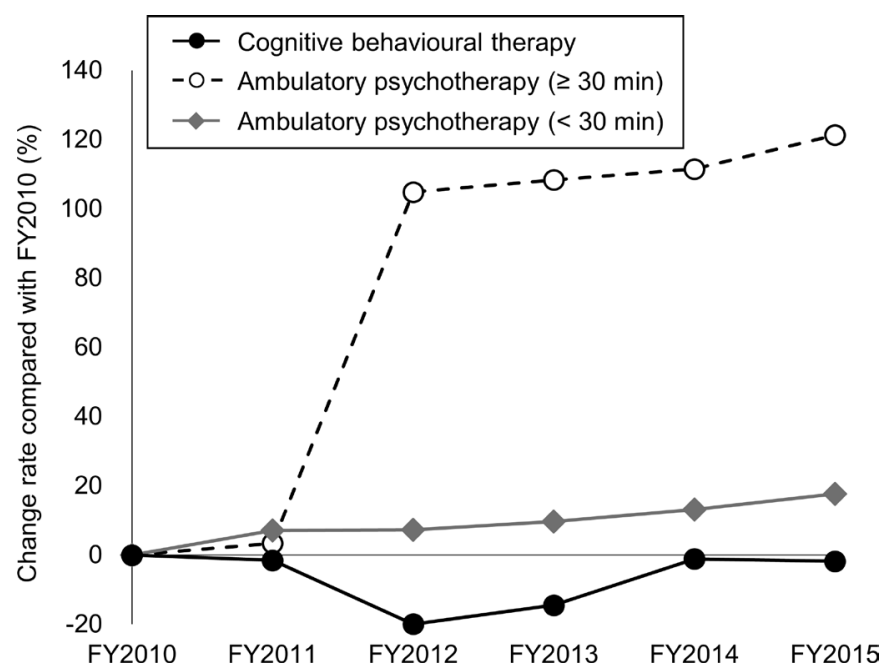

Figure 1 Trends over time for the number of outpatients who received psychotherapy in Japan. FY, fiscal year. 


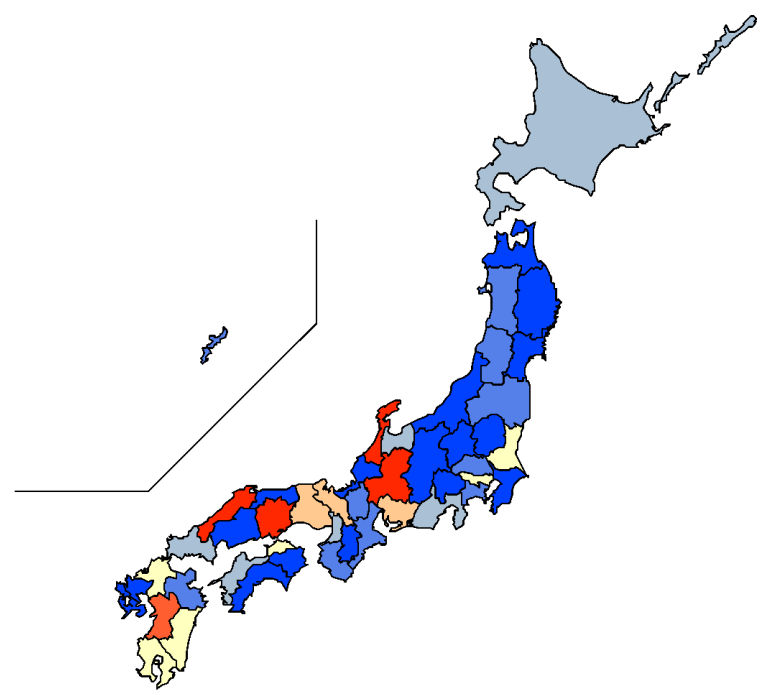

Cognitive behavioural therapy

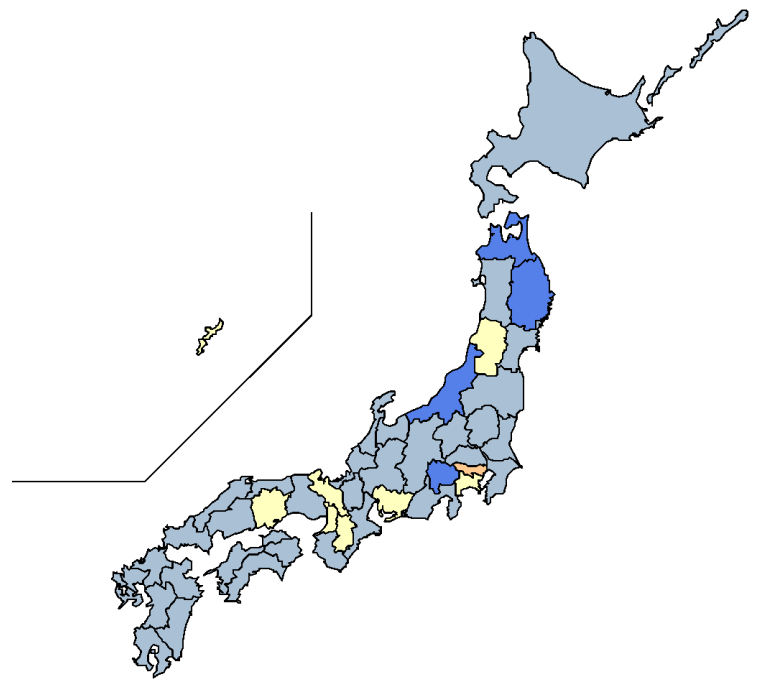

Ambulatory psychotherapy ( $\geq 30 \mathrm{~min}$ )

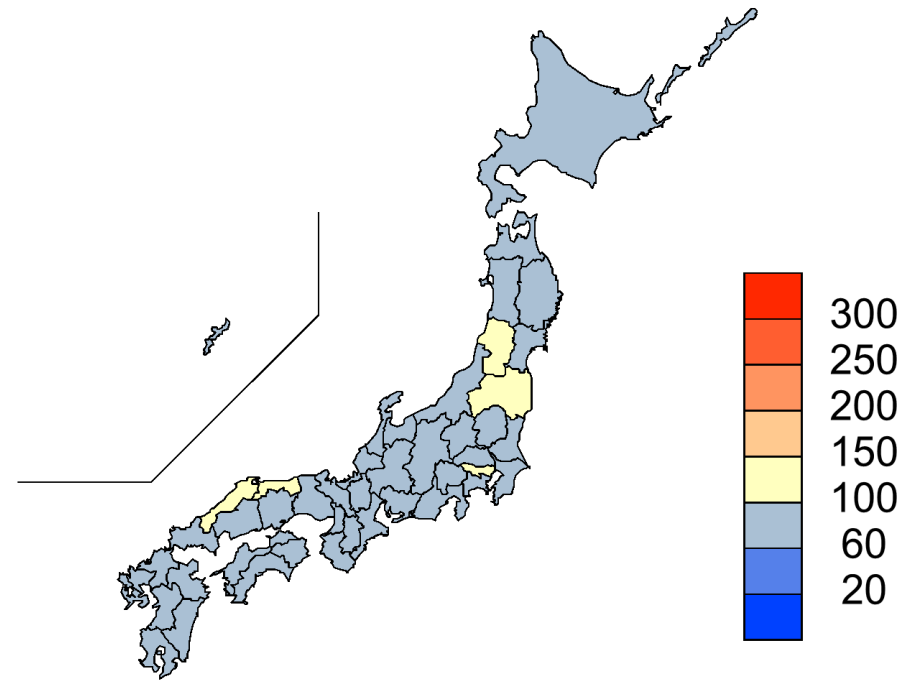

Ambulatory psychotherapy (<30 min)

Figure 2 Geographical distribution of standardised claim ratio (SCR) for the number of outpatients who received psychotherapy in Japan from fiscal years 2010 to 2015. The colour bar shows a degree of SCR. SCR of 100 indicates the national mean.

At the prefectural level, from FY2010 to FY2015, patients receiving CBT per 100000 population decreased (or remained at zero) in 32 of 47 prefectures, whereas patients receiving ambulatory psychotherapy per 100000 population increased in all prefectures. Figure 2 shows the SCR for the number of patients who received each psychotherapy in the study period. There was a maximum 424.7fold difference in SCR between the highest $(\mathrm{SCR}=585.2$ in Ishikawa) and lowest ( $\mathrm{SCR}=1.4$ in Tokushima) prefectures. Meanwhile, there was a maximum 3.4-fold difference in SCR of ambulatory psychotherapy (see online supplementary table 2 ).

In terms of the relationship between regional factors and the provision of CBT, the number of patients who received CBT per 100000 population was associated significantly with the number of registered CBT institutions per 100000 population $(\mathrm{p}<0.01)$ (table 2). If the number of registered institutions per 100000 population increased by 1 , the number of patients increased by $23.1 \quad(\mathrm{SE}=3.4)$ patients per 100000 population. The other factors were not associated with the number of CBT patients per 100000 population or SCR for CBT (tables 2 and 3).

\section{DISCUSSION}

This is the first study to use the nationwide claim database to demonstrate in detail the provision status of CBT in Japan in the first 6years (FY2010-2015) after its inclusion in the national health insurance scheme. Our results show that (a) approximately 60000 patients received CBT during the study period; (b) the number of patients receiving CBT was highest in the first year $(-1.8 \%$ from FY2010 to FY2015); (c) the number of patients receiving 
Table 2 Results of ecological analysis on factors associated with the number of patients who received CBT per 100000 population (FY2010-2015)

\begin{tabular}{llccccc}
\hline & & Estimate & SE & Degree of freedom & T value & P value \\
\hline Number of registered CBT & Intercept & -5.0 & 2.6 & 46 & -1.9 & 0.06 \\
institutions per 100 000 population & Slope & 23.1 & 3.4 & 137 & 6.7 & $<0.01^{*}$ \\
\multirow{2}{*}{$\begin{array}{l}\text { Number of psychiatrists per 100 000 } \\
\text { population }\end{array}$} & Intercept & 4.4 & 5.9 & 46 & 0.7 & 0.46 \\
& Slope & 0.3 & 0.4 & 91 & 0.6 & 0.52 \\
\hline
\end{tabular}

*Indicates significant difference.

CBT, cognitive behavioural therapy; FY, fiscal year.

CBT per 100000 decreased (or remained at zero) in most prefectures (32 out of 47); (d) based on SCR, there was a maximum 420 -fold regional difference in the number of CBT patients between prefectures and (e) the number of registered CBT institutions was significantly associated with the number of patients receiving CBT. Overall, the current study indicates that the provision of CBT did not increase under Japan's health insurance scheme from FY2010 to FY2015.

The reasons that the provision of CBT reached a plateau in Japan could be due to strict requirements and low medical fees for therapists/institutions in the national health insurance system. For example, a CBT provider must be a medical doctor, must target only outpatients with mood disorder, and the provider's institution must be registered to the Regional Bureau of Health and Welfare of Japan (table 1). In terms of medical fees, CBT fees in Japan are substantially lower than those in Western countries. For example, in Japan, maximum fee for CBT is 5000 Japanese yen (JPY) per session (equal to 33 Great Britain pounds $(\mathrm{GBP})$, exchange rate: $1 \mathrm{GBP}=150 \mathrm{JPY})$, whereas the fee in England is $97 \mathrm{GBP}$ (equal to 14,550 JPY) per session. ${ }^{34}$ Moreover, CBT fees are almost the same as ambulatory psychotherapy fees for sessions over $30 \mathrm{~min}$ despite the aforementioned restrictions (table 1). Thus, ambulatory psychotherapy sessions under 30 min yield the highest profits for medical doctors in Japan's national health insurance system. Indeed, Japanese psychiatrists see seven outpatients per hour in routine clinical practice. ${ }^{35}$ Furthermore, some studies have reported that the main obstacles in providing psychotherapy/CBT in Japan are a lack of time and profitability ${ }^{29}{ }^{30}$ Thus, more reasonable medical fees and requirements suitable to the actual conditions of routine clinical practice could motivate the

Table 3 Association between implementation of formal CBT training and SCR for CBT (FY2010-2015)

\begin{tabular}{llll}
\hline & Training(-) & Training(+) & P value \\
\hline Prefectures $(\mathrm{n})$ & 37 & 10 & - \\
$\begin{array}{l}\text { SCR for CBT } \\
\text { (mean } \pm \text { SE) }\end{array}$ & $98.0 \pm 23.0$ & $73.2 \pm 19.9$ & 0.59 \\
\hline
\end{tabular}

Degree of freedom $=45, \mathrm{t}$ value $=0.54$.

CBT, cognitive behavioural therapy; FY, fiscal year; SCR, standardised claim ratio. use of CBT under the national health insurance scheme in Japan. Although we focused mainly on outpatient settings here, CBT for inpatients should also be included in the national health insurance scheme because it is recommended for inpatients with some disorders as well as in many international guidelines.

This study focused on CBT but a large shift in ambulatory psychotherapy ( $\geq 30 \mathrm{~min})$ in FY2012 should be addressed. It seems that this large shift was caused by the revision of medical fee requirements for ambulatory psychotherapy in that year. Before the revision in FY2012, psychiatrists at any psychiatric institution were able to claim one type of ambulatory psychotherapy when they spent more than 60 min with a patient for the first visit. However, the revision imposed cooperation with local psychiatric emergency medical services (eg, holiday/ night medical examinations) on psychiatrists for this type of ambulatory psychotherapy. Because of this, many psychiatrists (especially those working at small psychiatric institutions) were no longer able to claim the optional fees for ambulatory psychotherapy applied on the first visit. As a result, it is possible that psychiatrists started claiming outpatients in the first visit as covered by 'ambulatory psychotherapy ( $\geq 30 \mathrm{~min}$ )'.

Our results also showed a maximum approximately 420-fold difference in SCR for CBT between prefectures, so there was a large regional variation in CBT utilisation. In particular, SCR was low over the whole Tohoku region where effective treatment for psychiatric disorders is in high demand because of the high suicide rate ${ }^{36}$ On the other hand, one of the reasons for the large variation in SCR between prefectures may be that the total number of CBT patients in Japan is small. Therefore, if a single institution in a particular prefecture has many CBT patients, the SCR in that area would be overestimated because it is an indicator calculated from the national mean.

During the study period, formal CBT training had been implemented in 10 out of 47 prefectures. We predicted that the implementation of formal CBT training would be associated with SCR for CBT, but there was no association between these variables. The training consists of a 2-day onsite workshop and continuous online clinical supervision. Thus, one of the reasons that medical doctors in regions with no workshop training can continue to provide CBT may be because they can receive continuous 
online supervised instruction irrespective of area. There was also a significant association between the number of CBT patients per 100000 population and the number of registered CBT institutions per 100000 population. These results suggest that an increase in institutions that have formally-trained medical doctors and that meet institutional criteria for CBT could lead to a wide-scale dissemination of CBT under the national health insurance scheme.

To make CBT much more widely available, recent success in England also offers lessons that are likely applicable to Japan. In England, the number of patients with depression finishing CBT increased by $181.2 \%$ from FY2013 to FY2018 (28814 patients to 81038 patients). ${ }^{37}$ One of the reasons for this success could be an increase in the number of therapists through a government-funded 1-year systematic training, IAPT (over new 7000 therapists have trained in FY2015 $5^{38}$ ). The NHS has instigated this initiative based on data including economic evaluation in demonstration sites. ${ }^{39}$ Towards a successful dissemination of CBT, it is necessary to continue accumulating research-based data, advocating and appealing for the required funding and organisational support, and train CBT therapists. ${ }^{22}$ Healthcare policymakers may require data showing that CBT for mental disorders will in fact reduce costs to healthcare systems in the long term. Future studies should therefore attempt to demonstrate the long-term cost-effectiveness of CBT for various mental disorders in Japanese clinical settings. ${ }^{40}$

The strength of this study is that the data source was the NDB, a comprehensive database which covers all electronic claims in Japan's national health insurance system. However, there are also several limitations. First, the NDB does not store medical treatment data for any treatment provided outside the national system (eg, private counselling). Although CBT for depression in Japan is mainly provided by psychologists in routine care, ${ }^{41}$ it is not covered by the national health insurance system. Thus, there is a possibility that more CBT was actually conducted across Japan, even in prefectures with few CBT patients under the health insurance scheme. Second, we selected ambulatory psychotherapy as a reference to CBT because both psychotherapies target only outpatients and both are provided only by a medical doctor. However, this is still not an ideal reference because the provider and target of both psychotherapies are not perfect analogues. Third, our ecological analysis was conducted using specific variables. There could be other factors which affect the provision of CBT. Finally, the observation period in this study is slightly outdated due to a delayed acquisition process for NDB data from the MHLW. However, we believe that the current study still has academic value for the following reasons. First, this is the first study to demonstrate the status of CBT in Japan using comprehensive public data. Second, our findings would be useful to future researchers/policymakers reviewing the status of CBT in Japan after the observation period of this study. Because of these limitations, further updates on the NDB
(FY2016-) and the questionnaire survey of registered CBT institutions are required.

Overall, this study revealed some issues regarding the provision of CBT in Japan in the first 6years (FY20102015) after its coverage in the national health insurance scheme. The number of patients receiving CBT in Japan did not increase probably due to unprofitability for therapists/institutions in Japan's current healthcare insurance system. Further, there were large regional variations in CBT status between the 47 prefectures and a significant association between the number of CBT patients per 100000 population and the number of registered CBT institutions per 100000 population. These findings suggest that an appropriate evaluation of medical fees for CBT in clinical settings and supporting hospitals and/or clinics in meeting the institutional criteria for CBT would help in the widespread utilisation of CBT in Japan. Further research into the status of CBT in Japan after the observation period of this study (FY2016-) and a questionnaire survey of registered CBT institutions are required to get more detailed information on the dissemination of CBT.

\section{Author affiliations}

${ }^{1}$ Graduate School of Medicine and Veterinary Medicine, University of Miyazaki,

Miyazaki, Japan

${ }^{2}$ Department of Nursing, Graduate School of Health Sciences, Kobe University, Kobe, Japan

${ }^{3}$ School of Nursing, Faculty of Medicine, University of Miyazaki, Miyazaki, Japan ${ }^{4}$ Department of Animal and Grassland Sciences, Faculty of Agriculture, University of Miyazaki, Miyazaki, Japan

${ }^{5}$ Center for Animal Disease Control, University of Miyazaki, Miyazaki, Japan ${ }^{6}$ Center for Next Generation of Community Health, Chiba University Hospital, Chiba, Japan

${ }^{7}$ Division of Biostatistics, Kurume University School of Medicine, Kurume, Japan ${ }^{8}$ Clinical Research Support Center, University of Miyazaki Hospital, Miyazaki, Japan ${ }^{9}$ Division of Psychiatry, Department of Clinical Neuroscience, Faculty of Medicine, University of Miyazaki, Miyazaki, Japan

Acknowledgements The authors are grateful to Mr. Richard White for checking the English and to Ms. Chieko Fujiyama for supporting data collection and entry.

Contributors Acquisition of data: $\mathrm{YH}$ and NY; analysis and interpretation of data: $\mathrm{YH}, \mathrm{NY}, \mathrm{YS}, \mathrm{HT}, \mathrm{KY}, \mathrm{YK}, \mathrm{YA}, \mathrm{TY}$, and Yl; drafting the manuscript: YH, NY, and YS. All authors critically reviewed the manuscript and approved the final version.

Funding This work was supported by a FY2017 (21st) research grant for young researchers from the Japanese Institute for Health Economics and Policy (https:// www.ihep.jp) (to NY).

Map disclaimer The depiction of boundaries on the map(s) in this article do not imply the expression of any opinion whatsoever on the part of BMJ (or any member of its group) concerning the legal status of any country, territory, jurisdiction or area or of its authorities. The map(s) are provided without any warranty of any kind, either express or implied.

Competing interests NY has received a speaking honorarium from Gakken Medical Support, and writing honoraria from Igaku Shoin, Nihon-Hyouronsha, Sogensha, and Medical Friend. The other authors declare that they have no conflicts of interest.

Patient consent for publication Not required.

Ethics approval The study protocol was reviewed and approved by the Ethics Committee of the University of Miyazaki (reference number: 0-0017). We also got permission to use a dataset extracted from the NDB (reference number: 1025-1). Written informed consent was waived because all patient records were automatically anonymized prior to storage in NDB (i.e. no one can identify specific patients). 
Provenance and peer review Not commissioned; externally peer reviewed.

Data availability statement Data may be obtained from a third party and are not publicly available. The data used in this study are from the Ministry of Health, Labour and Welfare (MHLW) in Japan, and therefore, users of these data are strictly limited to those who obtain official permission from the MHLW, in accordance with Japanese Article 33 (Provision of Questionnaire Information) of the Statistics Act, by the Statistic Bureau, Ministry of Internal Affairs and Communications. Qualified researchers who would like to request access to the data should contact the Statistics and Information Department of the MHLW. Please refer to the following URL: http://www.mhlw.go.jp/toukei/sonota/chousahyo.html.

Open access This is an open access article distributed in accordance with the Creative Commons Attribution Non Commercial (CC BY-NC 4.0) license, which permits others to distribute, remix, adapt, build upon this work non-commercially, and license their derivative works on different terms, provided the original work is properly cited, appropriate credit is given, any changes made indicated, and the use is non-commercial. See: http://creativecommons.org/licenses/by-nc/4.0/.

\section{ORCID iD}

Naoki Yoshinaga http://orcid.org/0000-0002-4438-9746

\section{REFERENCES}

1 Mathers CD, Loncar D. Projections of global mortality and burden of disease from 2002 to 2030. PLoS Med 2006;3:e442.

2 Steel Z, Marnane C, Iranpour C, et al. The global prevalence of common mental disorders: a systematic review and meta-analysis 1980-2013. Int J Epidemiol 2014;43:476-93.

3 Ishikawa H, Tachimori H, Takeshima T, et al. Prevalence, treatment, and the correlates of common mental disorders in the mid 2010's in Japan: the results of the world mental health Japan 2nd survey. $J$ Affect Disord 2018;241:554-62.

4 Kawakami N, Tachimori H, Takeshima T. Report of the world mental health Japan survey 2nd (2013-2015), 2016. Available: wmhj2.jp/ WMHJ2-2016R.pdf [Accessed 20 Dec 2017]

5 Butler A, Chapman J, Forman E, et al. The empirical status of cognitive-behavioral therapy: a review of meta-analyses. Clin Psychol Rev 2006;26:17-31.

6 Sado M, Knapp M, Yamauchi K, et al. Cost-Effectiveness of combination therapy versus antidepressant therapy for management of depression in Japan. Aust N Z J Psychiatry 2009;43:539-47.

7 Fujisawa D, Nakagawa A, Tajima M, et al. Cognitive behavioral therapy for depression among adults in Japanese clinical settings: a single-group study. BMC Res Notes 2010;3:160.

8 Cuijpers P, Berking M, Andersson G, et al. A meta-analysis of cognitive-behavioural therapy for adult depression, alone and in comparison with other treatments. Can J Psychiatry 2013;58:376-85

9 Wiles N, Thomas L, Abel A, et al. Cognitive behavioural therapy as an adjunct to pharmacotherapy for primary care based patients with treatment resistant depression: results of the cobalt randomised controlled trial. The Lancet 2013;381:375-84.

10 Nakagawa A, Mitsuda D, Sado M, et al. Effectiveness of supplementary cognitive-behavioral therapy for PharmacotherapyResistant depression. J Clin Psychiatry 2017;78:1126-35.

11 Takagaki K, Okamoto Y, Jinnin R, et al. Enduring effects of a 5week behavioral activation program for subthreshold depression among late adolescents: an exploratory randomized controlled trial. Neuropsychiatr Dis Treat 2018;14:2633-41.

12 Mavranezouli I, Mayo-Wilson E, Dias S, et al. The cost effectiveness of psychological and pharmacological interventions for social anxiety disorder: a model-based economic analysis. PLoS One 2015;10:e0140704.

13 Sava FA, Yates BT, Lupu V, et al. Cost-Effectiveness and costutility of cognitive therapy, rational emotive behavioral therapy, and fluoxetine (Prozac) in treating depression: a randomized clinical trial. $J$ Clin Psychol 2009;65:36-52.

14 National Institute for clinical Excellence (NICE). Clinical guidelines [CG90]. Depression in adults: recognition and management 2009.

15 American Psychiatric Association (APA). Practice guideline for the treatment of patients with acute stress disorder and posttraumatic stress disorder second edition, 2010. Available: www. psychiatryonline.org/pb/assets/raw/sitewide/practice_guidelines/ guidelines/panicdisorder.pdf [Accessed 20 Dec 2017].

16 Hay P, Chinn D, Forbes D, et al. Royal Australian and New Zealand College of Psychiatrists clinical practice guidelines for the treatment of eating disorders. Aust N Z J Psychiatry 2014;48:977-1008.

17 Parikh SV, Quilty LC, Ravitz P, et al. Canadian network for mood and anxiety treatments (CANMAT) 2016 clinical guidelines for the management of adults with major depressive disorder. Can $\mathrm{J}$ Psychiatry 2016;61:524-39.

18 Japanese Society of Mood Disorders. Guideline for treatment of major depressive disorder, 2016[in Japanese]. Available: www. secretariat.ne.jp/jsmd/mood_disorder/img/160731.pdf [Accessed 20 Dec 2017].

19 McHugh RK, Whitton SW, Peckham AD, et al. Patient preference for psychological vs pharmacologic treatment of psychiatric disorders. $J$ Clin Psychiatry 2013;74:595-602.

20 Dwight-Johnson M, Sherbourne CD, Liao D, et al. Treatment preferences among depressed primary care patients. J Gen Intern Med 2000;15:527-34.

21 Shafran R, Clark DM, Fairburn CG, et al. Mind the gap: improving the dissemination of CBT. Behav Res Ther 2009;47:902-9.

22 Gunter RW, Whittal ML. Dissemination of cognitive-behavioral treatments for anxiety disorders: overcoming barriers and improving patient access. Clin Psychol Rev 2010;30:194-202.

23 Department of Health. IAPT three-year report: the first million patients., 2012. Available: webarchive.nationalarchives.gov.uk/ 20160302155226/http://www.iapt.nhs.uk/silo/files/iapt-3-year-report. pdf [Accessed 30 Dec 2019].

24 NHS Digital. Psychological therapies; annual report on the use of IAPT services: England 2018-19, 2019. Available: files.digital.nhs. uk/1C/538E29/psych-ther-2018-19-ann-rep.pdf [Accessed 30 Dec 2019].

25 Ono Y, Furukawa TA, Shimizu E, et al. Current status of research on cognitive therapy/cognitive behavior therapy in Japan. Psychiatry Clin Neurosci 2011;65:121-9.

26 International Narcotics Control Board. Report of the International Narcotics Control Board on the Availability of Internationally Controlled Drugs: Ensuring Adequate Access for Medical and Scientific Purposes., 2010. Available: www.incb.org/documents/ Publications/AnnualReports/AR2010/Supplement-AR10_availability_ English.pdf [Accessed 20 Dec 2017].

27 Yoshio T. The trend for megadose polypharmacy in antipsychotic pharmacotherapy: a prescription survey conducted by the psychiatric clinical pharmacy Research Group. Seishin Shinkeigaku Zasshi 2012;114:690-5. [in Japanese].

28 Okumura Y, Shimizu S, Matsumoto T. Prevalence, prescribed quantities, and trajectory of multiple prescriber episodes for benzodiazepines: a 2-year cohort study. Drug Alcohol Depend 2016;158:118-25.

29 Fujisawa D, Nakagawa A, Sado M, et al. Current status and dissemination of psychotherapies in Japan. Japan Ministry of Health and Labor 2006. [in Japanese].

30 Takahashi F, Takegawa S, Okumura Y, et al. Actual condition survey on the implementation of Cognitive Behavioral Therapy at psychiatric clinics in Japan., 2018[in Japanese]. Available: www.ftakalab.jp/ wordpress/wp-content/uploads/2011/08/japancbtclinic_report.pdf [Accessed 9 Jan 2018].

31 Japanese Ministry of Health, Labour and Welfare. Status of dissemination of electronically submitted claims, 2015[in Japanese]. Available: www.mhlw.go.jp/file/06-Seisakujouhou-12400000Hokenkyoku/0000099002.pd [Accessed 20 Dec 2017].

32 Nakayama T, Imanaka Y, Okuno Y, et al. Analysis of the evidencepractice gap to facilitate proper medical care for the elderly: investigation, using databases, of utilization measures for national database of health insurance claims and specific health checkups of Japan (NDB). Environ Health Prev Med 2017;22:51.

33 Sato I, Yagata H, Ohashi Y. The accuracy of Japanese claims data in identifying breast cancer cases. Biol Pharm Bull 2015;38:53-7.

34 Curtis L, Burns A. Unit costs of health and social care 2016, personal social services research unit. Canterbury: University of Kent, 2016. www.pssru.ac.uk/project-pages/unit-costs/unit-costs-2016/. (accessed 20 Dec 2017).

35 Nakagawa A, Williams A, Sado M, et al. Comparison of treatment selections by Japanese and US psychiatrists for major depressive disorder: a case vignette study. Psychiatry Clin. Neurosci 2015;69:553-62.

36 Japanese Ministry of Health, Labour and Welfare. Number of suicide based on statistics report by National police agency, 2019[in Japanese]. Available: www.mhlw.go.jp/content/201812-sokuhou.pdf [Accessed 25 Jan 2019].

37 NHS Digital. Psychological therapies, annual reports on the use of IAPT services, 2019. Available: digital.nhs.uk/data-andinformation/publications/statistical/psychological-therapiesannual-reports-on-the-use-of-iapt-services [Accessed $30 \mathrm{Dec}$ 2019].

38 Clark DM. Realizing the mass public benefit of evidence-based psychological therapies: the IAPT program. Annu Rev Clin Psychol 2018;14:159-83. 
39 Clark DM, Layard R, Smithies R, et al. Improving access to psychological therapy: initial evaluation of two UK demonstration sites. Behav Res Ther 2009;47:910-20.

40 Yoshinaga N, Kubota K, Yoshimura K, et al. Long-Term effectiveness of cognitive therapy for refractory social anxiety disorder: one-year follow-up of a randomized controlled trial. Psychother Psychosom 2019;88:244-6.

41 Sato H, Tanno Y. The Effect of Cognitive Behavioral Therapy for Depression Delivered by Japanese Psychologists : A Systematic Review. Japanese journal of behavior therapy 2012;38:157-67. 